\title{
Facts and Values in Psychiatric Practice: the theme of the 2006 national psychiatry congress
}

The President of the South African Society of Psychiatrists (SASOP), Professor Merryll Vorster, requested that practical ethics be incorporated in the formulation of a theme for the 2006 national congress of SASOP. Consequently, the organising committee resolved that the theme be 'Facts and Values in Psychiatric Practice'. The theme concerns the complexities of scientific evidence as well as the complexities of the ethical and various other values with which psychiatrists and other mental health practitioners are dealing at the coalface of psychiatric practice.

Scientific endeavours informing us on the relevant facts about diagnosis, treatment, prognosis, and other management aspects are critically important for psychiatric practice. It would be inadequate, if not dangerous and irresponsible, to base clinical decisions on merely 'my experience', 'how I feel', anecdotes of successes and failures, or a previous good/bad turn of events.

Scientific findings in medicine including psychiatry, however, have become abundant and complex. Evidence-based medicine attempts to address this difficulty by examining relevant clinical research from both patient-centred research and the basic sciences of medicine for the accuracy and precision of diagnostic tests (including the clinical examination), the power of prognostic markers, and the efficacy and safety of therapeutic, rehabilitative and preventive regimens. New evidence from clinical research moreover both invalidates previously accepted diagnostic tests and treatments and replaces them with new ones that are more powerful, more accurate, more efficacious, and safer.

Although evidence-based medicine is about dealing with the complexities of facts, it also concerns values - in particular and foremost scientific values. After all, evidence-based medicine is about the best research evidence.

All the same, the champions of evidence-based medicine, Sackett et al., call explicitly upon more than merely the best facts.' They go so far as defining evidence-based medicine as the integration of best research evidence with clinical expertise and patient values. By clinical expertise they mean the ability to use our clinical skills and past experience to identify each patient's unique health state and diagnosis, the individual risks and benefits of potential interventions, and the patient's personal values and expectations; and by patient values they mean the unique preferences, concerns and expectations each patient brings to a clinical encounter and which must be integrated into clinical decisions if they are to serve the patient.

Values, however, are a different kettle of fish. In dealing with facts we aim for conformity and consensus in coming to the best evidence, but some clinically important values are undermined when they are dealt with in the same way. Diversity of values is a given and is treasured for good reasons. Of course there are also commonly shared values about which we agree (relatively easily). The thorny challenge, however, is dealing with legitimately diverse values in clinical practice. Values-based practice provides the pointers for this. The details thereof are explicated substantially with clinical examples in the newly published Oxford Textbook of Philosophy and Psychiatry, which is in my opinion the best comprehensive publication in the subject area of philosophy and psychiatry since the publication of Karl Jaspers' General Psychopathology almost a century ago. ${ }^{2}$

Psychiatrists are far better trained on the facts, however. Fending off an 'agnosia' for values requires that we learn to see and recognise the kinds and scope of values that pertain in psychiatric practice. We need to see and recognise more than mere bioethical values, prescriptive values, normative values, quasi-legal values, principles, virtues, ideals, personal values and religious values. We need to see and recognise societal, cultural, and aesthetic values; values of good and bad, right and wrong, of duties, obligations, responsibility, etc. Too narrow a view on the kinds and scope of values, in contrast, would preclude their recognition. ${ }^{3}$

How do I identify and even uncover the (hidden) values that pertain in making psychiatric diagnoses and suggesting treatments? And, what do I do about them once identified? These loaded questions prompt us to realise that the skills and knowledge to work with diversity of values in psychiatry are lagging behind in comparison with the knowledge and skills that we have in dealing with facts.

Our congress provides the opportunity to put our heads together in considering the facts and the values that are relevant in psychiatric practice. Importantly, the congress provides opportunity to strengthen collegial and friendly ties and to learn from another. Such putting heads together at the congress will bear fruits in the form of papers that are keenly received for publication in our official SASOP journal, the thriving South African Journal of Psychiatry.

\section{C $W$ van Staden}

Editor

1. Sackett DL, Straus SE, Scott Richardson W, Rosenberg W, Haynes RB. Evidence Based Medicine: How to Practice and Teach EBM. 2nd ed. Edinburgh: Churchill Livingstone, 2000.

2. Fulford KWM, Thornton T, Graham G. Oxford Textbook of Philosophy and Psychiatry. Oxford: Oxford University Press, 2006

3. Van Staden CW. The need for trained eyes to see facts and values in psychiatric diagnosis. World Psychiatry 2005; 4: 94 